\title{
Effects of Polypropylene Fibers on the Shear Strength of Sandy Soil
}

\author{
Mousa F. Attom, Adil K. Al-Tamimi \\ Civil Engineering Department, College of Engineering, American University of Sharjah, Sharjah, UAE \\ E-mail:mattom@aus.edu \\ Received March 1, 2010; revised March 27, 2010; accepted April 20, 2010
}

\begin{abstract}
This paper presents the effect of two types of polypropylene fibers on shear strength parameters of sandy soil. To achieve the goals of this research, a sandy soil was obtained from a depth of $40 \mathrm{~cm}$ from the natural ground surface around American University of Sharjah. Two types of polypropylene fibers; one highly flexible with flat profile and the other with relatively high stiffness and crimpled profile were used in this study with four different aspect ratios (L/D) for each type. The initial physical properties of the sand such as specific gravity, angle of internal friction and shear strength were obtained in accordance with American Standard for Testing and Materials (ASTM). The sandy soils were mixed with the two types of fibers at different percentages by dry weight of the sand and four different aspect ratios. The test results of the study showed that the shear strength of the sand increased with increasing the flexible flat profile fibers content. Also it was noticed that by increasing the aspect ratio of the flexible flat profile the angle of internal friction and the shear strength increased. The crimpled profile fiber increased the shear strength of the sand under high normal load and has small or no effect on shear strength of the sand at low aspect ratio under low normal load.
\end{abstract}

Keywords: Sand, Fibers, Angle of Internal Friction, Shear Strength, Aspect Ratio

\section{Introduction}

Due to the increasing cost of high quality materials needed for different geotechnical projects, engineers try to improve the physical properties of local soils throughout different methods and techniques. The word improvement means to increase the shear strength, reducing settlements, resists harsh environment conditions such as thawing and freezing, and decreases or eliminates all problems associated with weak soils. Soil stabilization could be applied to both sandy and clayey soil through mechanical and chemical methods. There are many common methods-mechanical or chemical-found in the literatures that were used to improve the physical properties of the soils. [1] showed that the increase of the compaction energy effort will increase the shear strength properties of the clayey soils. [2] used gypsum as an additive for stabilization of clay against swelling. He concluded that the gypsum can be used as a stabilizing agent for expansive clay against swelling effectively. AlRawas et al. [3] indicated that the addition of lime and cement will reduce both the swell potential and swelling pressure of expansive clayey soils. [4] used natural re- sources such as volcanic ash, ground natural lime, cement and their combination to stabilize soil for construction application. [5] studied the effect of silica fume on fine grain soils exposed to freeze and thaw. He found that the addition silica fume can be successfully used to reduce the effect of freezing and thawing cycles on strength and permeability of fine grained soils. In addition to these methods, other methods also exist such as wet-dry cycles and thermal methods $[6,7]$.

Recently, engineers started to use different types of fiber in soil stabilizations. These fibers are found in the market as short, discrete materials with different aspect ratio and they can be mixed randomly with the soil, as cement, lime, or other additives at different percentages. The main reason of using randomly oriented fibers is to maintain strength isotropy and the lack of potential weak planes that may develop parallel to oriented reinforcement [8,9]. Fatani et al. [10] studied the effect of both aligned and randomly oriented metallic fibers on silty sand. It was found that mixing fibers with silty sand soil will increase the peak strength and residual strength $100 \%$ and $300 \%$ respectively over the untreated soil. Ziegler et al. [11] studied the effect of short polymeric 
fibers on crack behavior of clay subjected to drying and wetting conditions. He concluded that the addition of fibers to the clay soil is very effective in reducing the amount of desiccation cracking and increasing the tensile strength. [12] in his study indicated that the residual shear strength angle of sand will increase by mixing sand with discrete fiber. Esna-ashari [13] used cord waste fiber to reinforce the sandy soil. They found that the inclusion of tire cord fiber can change significantly the brittle behavior of sandy soil to more ductile and also increased both the peak strength and angle of internal friction of sand. Gray and Ohashi [14] and Park and Tan [15] used randomly oriented discrete fibers in their research to reinforce sand. Freitag [16] mixed the fiber with clayey soil and showed that addition of fiber will increase the strength and ductility than plain clayey soil. The addition of nylon fiber by Kumar and Tabor [17] resulted in significant increase in the residual strength of silty clay soil. The test by Cai et al. [18] reported that there is a significant improvement on the engineering properties of the fiber-lime treated soil. Due to the encouraging findings of using discrete fiber with both sandy and clayey soils, the fibers are used in different construction applications such as retaining structures, embankments, subgrade and landfill liners and covers. The main objective of this study is to investigate the effect of two types of fibers on some physical properties of sandy soil. The parameters investigated in this study include shear strength properties and angle of internal friction at different fiber percentages and aspect ratios.

\section{Polypropylene Fiber Type A \& B}

Two types of fibers are used in the research; both fibers are extruded from a natural Polypropylene homo polymer. The two fibers were given symbols A and B in the discussion. Type $\mathrm{A}$ is formed into a flat profile with high flexibility where type B formed into a crimped profile with high relative stiffness in order to anchor it with the matrix. The combination between the large number of fibers per kg, its shape and anchoring capability with the matrix, would provide a toughness and ductility to the material. Both types have high resistance to acid/alkali attack and are therefore suitable for use in wet underground conditions. Table 1 shows the physical properties of the two types of fibers used in this research.

\section{Experimental Program}

A sandy soil was selected from around American University at Sharjah and brought to soil testing laboratory.
The soils were extracted from $40 \mathrm{~cm}$ in depth from original ground surface. The initial physical properties of the sandy soil such as gradation ASTM D-422, specific gravity ASTM D-854, and maximum dry density and optimum water content ASTM D-1557 were determined in accordance with American Standard for Testing and Materials (ASTM) standard procedures. Table 2 shows the initial physical properties of the sandy soil used in the study. The sandy soil was mixed with the two types of fibers at different percentages by dry weight of the sand and different aspect ratios. The percentages of the fibers are $1 \%, 2 \%, 3 \%, 4 \%$, and dry weight of the sand. The aspect ratio index of the fibers, which is dimensionless, was used in the analysis instead of the length. At each percentage, four different aspect ratios (L/D) of the fibers were used with constant diameter and variable length. Because of the difference in diameter between type A and type B fiber four different aspect ratios were used for each type. The aspect ratios used for type A are $38.5,77,115.5$ and 154 while the aspect ratio for type $\mathrm{B}$ are $10.4,20.8,31.2$ and 41.7 .

Table 1. Properties of the two types of fibers used in this study.

\begin{tabular}{lcc}
\hline \multicolumn{1}{c}{ Characteristics } & Fiber & Fiber \\
\hline & Type A & Type B \\
Fiber Cross section $\mathrm{mm}^{2}$ & 0.234 & 0.75 \\
Fiber length & $50 \mathrm{~mm}$ & $40 \mathrm{~mm}$ \\
Diameter & $0.13 \mathrm{~mm}$ & $0.48 \mathrm{~mm}$ \\
Tensile strength at yield $\left(\mathrm{N} / \mathrm{mm}^{2}\right)$ & 1004 & 250 \\
\hline
\end{tabular}

Table 2. Physical prosperities of the sand used in this study.

\begin{tabular}{|c|c|}
\hline Physical Properties & \\
\hline \multicolumn{2}{|l|}{ Shear Strength } \\
\hline Angle of Internal friction ( $\mathrm{deg}$ ) & 19 \\
\hline Cohesion $(\mathrm{kPa})$ & 0 \\
\hline \multicolumn{2}{|l|}{ Compaction } \\
\hline Maximum dry unit weight $\left(\mathrm{kN} / \mathrm{m}^{3}\right)$ & 17.9 \\
\hline Minimum dry unit weight $\left(\mathrm{kN} / \mathrm{m}^{3}\right)$ & 14.3 \\
\hline Optimum moisture content $(\%)$ & 12.8 \\
\hline \multicolumn{2}{|l|}{ Grain size distribution } \\
\hline Clay $(<2 \mu \mathrm{m})$ & 6 \\
\hline Silt $\quad(2 \mu \mathrm{m}-75 \mu \mathrm{m})$ & 18 \\
\hline Sand $(75 \mu \mathrm{m}-2 \mathrm{~mm})$ & 76 \\
\hline Effective size D10 (mm) & 0.007 \\
\hline$D 30(\mathrm{~mm})$ & 0.12 \\
\hline$D 60(\mathrm{~mm})$ & 0.33 \\
\hline \multicolumn{2}{|l|}{ Specific gravity of solid, $G_{s}$} \\
\hline$G_{s}$ & 2.66 \\
\hline
\end{tabular}


Enough number of samples was prepared at 95\% relative compaction and optimum moisture content with different fiber content. Predetermined amount of soil was obtained and mixed with the two types of fibers separately and compacted in the direct shear mold to obtain the $95 \%$ relative compaction. Direct shear test ASTM D-3080 was conducted on all sample under three normal loads. (28 kPa, $55 \mathrm{kPa}, 110 \mathrm{kPa})$. The remolded specimens were sheared under a constant strain rate and deformations were recorded throughout the experiment. To obtain the shear strength and the angle of internal friction of the sand-fiber mixture at each percentage three identical specimens were prepared and tested under three different normal loads.

\section{Results and Discussion}

\subsection{The Effect of Fibers on the Shear Strength, Angle of Internal Friction and Stress-Strain Relationships of the Sand}

Figures 1 and $\mathbf{2}$ depicts the shear strength behavior and stress-strain relationships of sandy soil mixed with the type $\mathrm{A}$ and type $\mathrm{B}$ fiber respectively at different percentages and under normal load equal to $28 \mathrm{kPa}$. Figure 1 concluded that the increase in the percentages of type A fiber will result in increasing the shear strength. Figure 2 showed the increase of type B fiber has a small or no effect on shear strength up to $3 \%$. The increase in the percentage of type $\mathrm{B}$ fiber more than $3 \%$ will result in decreasing the shear strength. The summary of the effect of adding both fiber A and fiber B on shear strength of sand under three normal loads was shown in Figure 3. This figure was obtained from the stress-strain relation from the direct shear test under different normal loads equal to $28 \mathrm{kPa}, 55 \mathrm{kPa}$ and $110 \mathrm{kPa}$ and for sand mixed

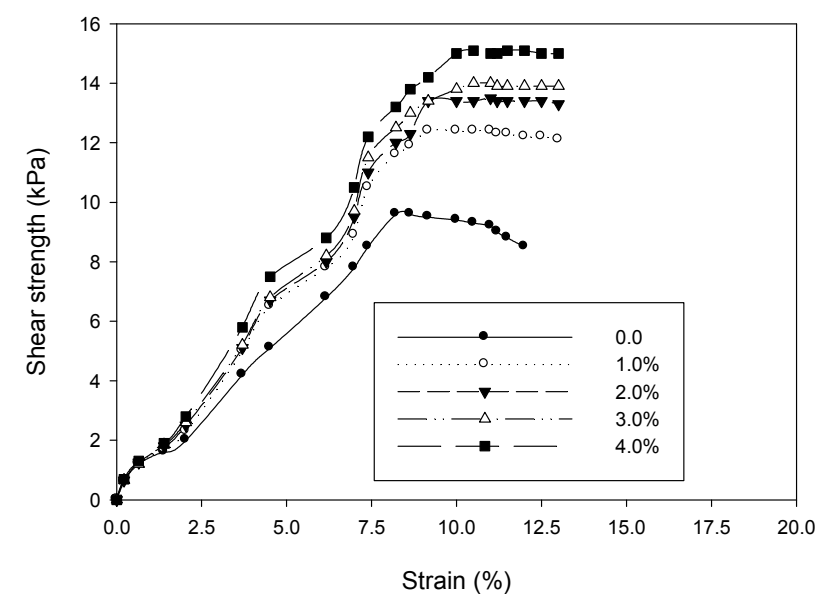

Figure 1. The effect of type A fiber on shear strength of sand under normal load equal to $28 \mathrm{kPa}$.

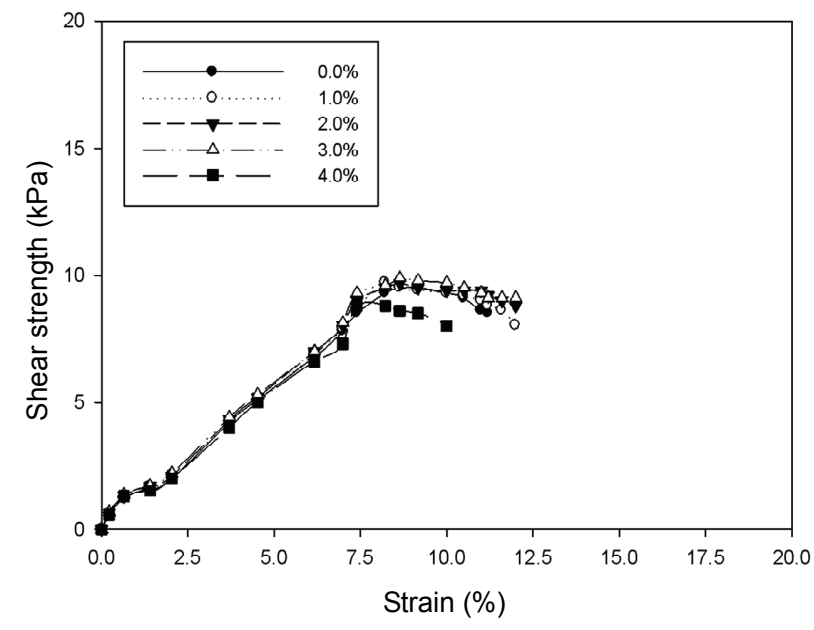

Figure 2. The effect of type $B$ fiber on shear strength of sand under normal load equal to $28 \mathrm{kPa}$.

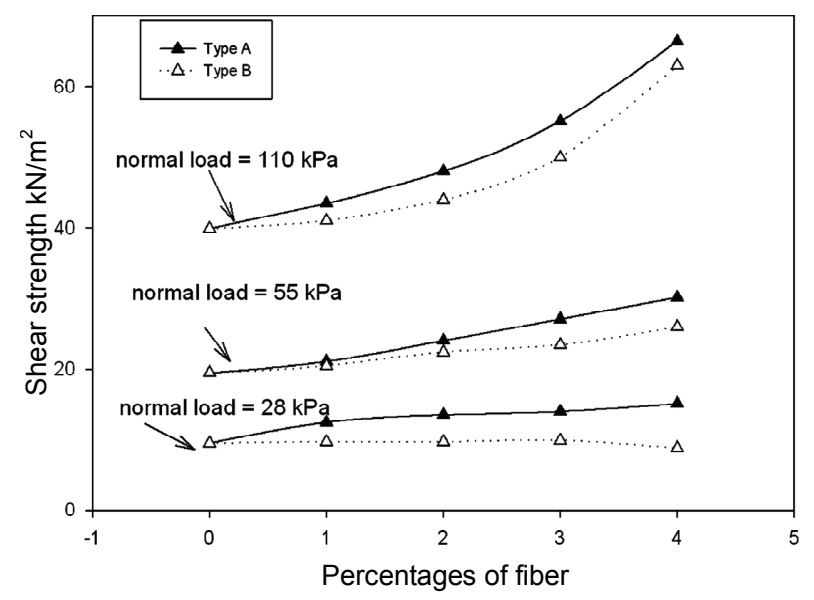

Figure 3. The effect of the fibers on the shear strength of the sand under three different normal loads.

with type A and type B respectively. This figure concludes that the addition of type A fiber will increase the shear strength of the sand under the three normal loads. The increase in the percentages of nylon fiber from $0.0 \%$ to $4 \%$ resulted in increasing the shear strength from $9.5 \mathrm{kPa}$ to $15.1 \mathrm{kPa}$ respectively, under normal load equal to $28 \mathrm{kPa}$. The addition of type A fiber up to $4 \%$ increased the shear strength of the sand up to $59 \%$. As the normal load increased the addition of type A resulted in increasing the shear strength. For example the shear strength of the sand increased from $39.9 \mathrm{kPa}$ to $66.4 \mathrm{kPa}$ when the type A fiber increased from $0.0 \%$ to $4.0 \%$ under normal load equal to $110 \mathrm{kPa}$. The percentages in shear strength increased is about $66.4 \%$ under normal load equal to $110 \mathrm{kPa}$ compares to $59 \%$ increased under normal load $28 \mathrm{kPa}$.

Different findings was noticed when the sand was mixed with type B fiber. As shown in Figure 4 the addition of Type B fiber up to $3 \%$ by dry weight of the sand 
has small or no effect on the shear strength at small normal load $(28 \mathrm{kPa})$. The addition of further fiber will result in decreasing the shear strength at $28 \mathrm{kPa}$ normal load. The shear strength decreased from $9.5 \mathrm{kPa}$ at $0.0 \%$ fiber content to $8.8 \mathrm{kPa}$ at $4 \%$ fiber content. However, addition of type B fiber resulted in increasing shear strength of sand at higher normal load. As shown in Figure 3 and at $55 \mathrm{kPa}$ and $110 \mathrm{kPa}$ normal loads the increase in the percentages in the type B fiber resulted in increasing the shear strength of the sand. The shear strength of sand under normal load equal to $55 \mathrm{kPa}$ increased from $19.5 \mathrm{kPa}$ and $26 \mathrm{kPa}$ when the percentages of $\mathrm{B}$ fiber increased from $0.0 \%$ to $4 \%$. The same behavior was noticed at higher normal loads. The shear strength increased under normal load $110 \mathrm{kPa}$ from $39.9 \mathrm{kPa}$ at $0.0 \%$ fiber content to $63 \mathrm{kPa}$ when the fiber content reached $4 \%$.

Another conclusion can be drawn from the stress strain relationship. It was noticed there was no peak behavior of sand due to addition of these two fibers. All specimen with both fiber reached fail without exercising peak strength.

The effect of adding both types of fibers on the angle of internal friction of the sand is shown in Table 3. It is clear in this table that the addition of type A fiber will increase the angle of internal friction of the sand under any loading level. The angle of internal friction increased as much as $49 \%$ when the Type A fiber increased by $4 \%$. Under normal load equal to $28 \mathrm{kPa}$. As the normal load increased the angle of internal friction increased to reach $64 \%$ under $110 \mathrm{kPa}$ normal load and 4\% fiber content. The effect of type B fiber is also shown in Table 3. The addition of type $B$ fiber has no effect on the angle of internal friction under small loading condition. As the normal load increased the addition of type B fiber will result in increasing the angle of internal friction. The angle of internal friction increased as much as $57 \%$ under $110 \mathrm{kPa}$ normal load and $4 \%$ fiber content. It can be concluded that the type $\mathrm{B}$ fiber has a very small on no effect on the angle of internal friction under small normal load and it has a significant effect on the angle of internal friction at large value of normal loading.

As it was mentioned earlier, the stress-strain relation curves were obtained from a direct shear test under $28 \mathrm{kPa}$ normal loads. Figure 1 shows the effect of type A fiber on the stress stain relation of sand. It is clear from this curve that as the percentages of type A fiber increased the strain failure increased too. The failure strain due to addition type A fiber increased from $8.6 \%$ to $10.0 \%$ and $11.5 \%$ when the fiber percentages increased from $0.0 \%$ to $2 \%$ and $4 \%$ respectively. This finding may conclude that the addition of type A fiber will increase the ductility of the sandy soil which is defined as the strain at failure of the soil specimen. The increase of the ductility of the soils with increasing the fiber contents is attributed to the effect of fibers inclusions in the sandy soil that improved the properties of the soil. Figure 2 shows the effect of type B fiber on the stress-strain relation of the sand. It was noticed that adding the type B fiber up to $3 \%$ has insignificant effect on ductility of the sand while adding the type $\mathrm{B}$ fiber more than $3 \%$ will result in decreasing the ductility of the sand. All the samples were failed about the same strain of $9.0 \%$ when mixed up to $3 \%$ of type B fiber. The samples mixed with $4 \%$ type B fiber failed at $7.5 \%$ strain. The effects of increasing the percentages of type A fiber and type B fiber on the failure strain are shown in Figure 4.

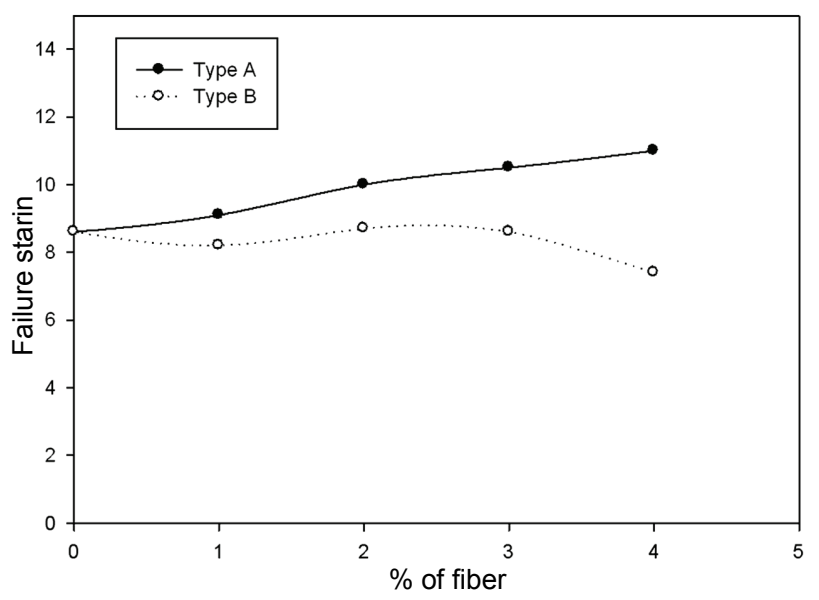

Figure 4. The effect of fibers on the failure starin of the sand under normal load $=28 \mathrm{kPa}$.

Table 3. The percentages increase in the angle of internal friction due to addition of fibers.

\begin{tabular}{ccccc}
\hline Load 28 kPa & \multicolumn{2}{c}{ Fiber A } & \multicolumn{2}{c}{ Fiber B } \\
\hline \% of fiber & $\varphi$ & \% increase & $\varphi$ & \% increase \\
\hline 0 & 19 & 0 & 19 & 0 \\
1 & 24 & 25.6 & 19 & 0.5 \\
2 & 26 & 35 & 19 & 0.5 \\
3 & 27 & 40 & 19 & 2 \\
4 & 28 & 49 & 18 & -8 \\
\hline Load $55 \mathrm{kPa}$ & Fiber A & & Fiber B & \\
\hline$\%$ of fiber & $\varphi$ & $\%$ increase & $\varphi$ & $\%$ increase \\
\hline 0 & 19 & 0 & 19 & 0 \\
1 & 21 & 1035 & 20 & 7 \\
2 & 24 & 24 & 22 & 17 \\
3 & 26 & 38 & 23 & 21 \\
4 & 29 & 52 & 25 & 33 \\
\hline Load $110 \mathrm{kPa}$ & Fiber A & & Fiber B & \\
\hline \% offiber & $\varphi$ & $\%$ increase & $\varphi$ & $\%$ increase \\
\hline 0 & 19 & 0 & 19 & 0 \\
1 & 22 & 13.7 & 20 & 7 \\
2 & 24 & 24 & 22 & 15 \\
\hline 3 & 27 & 40 & 24 & 28 \\
\hline
\end{tabular}




\subsection{The Effect of the Length of the Fiber on the Shear Strength of Sand}

The effects of length of both type A and type B fibers on shear strength of sand were studied in this research. The aspect ratio which is defined as the length over diameter ratio (L/D) was used herein instead of length alone as an indication for fiber length. Since the two types of fibers have different diameters, four aspect ratios were used for each type. The four aspect ratio for type $\mathrm{A}$ are $\mathrm{L} / \mathrm{D}=$ $38.5,77,115.5,154$ and for type $\mathrm{B}$ are $\mathrm{L} / \mathrm{D}=10.4,20.8$, $31.2,41.6$ respectively. The four aspect ratios were studied under three different loads $28 \mathrm{kPa}, 55 \mathrm{kPa}$ and $115 \mathrm{kPa}$. Figures 5 and $\mathbf{6}$ show the effect of aspect ratio on shear strength under two normal loads $28 \mathrm{kPa}$ and $110 \mathrm{kPa}$ respectively at 4\% type A fiber content by dry weight of the sand. It is clear from these two figures that the increase of aspect ratio resulted in increasing the shear strength. In Figure 5, the shear strength of sand increased from $11.4 \mathrm{kPa}$ to $14.5 \mathrm{kPa}$ when the aspect ratio increased from 38.5 to 154 under normal load $28 \mathrm{kPa}$. At the same time as shown in Figure 6, the shear strength increased from $45.1 \mathrm{kPa}$ to $66.1 \mathrm{kPa}$ when the aspect ratio increased from 38.5 to 154 under normal load equal to $110 \mathrm{kPa}$. The percentage in shear strength due to increase in aspect ratio from 38.5 to 154 varies between $27 \%$ and $47 \%$ under the three normal loads.

It was also noticed that increased in the aspect ratio of type A fiber resulted in increasing the ductility of the sand. This observation is clear in Figures 5 and 6. The sand in all samples at different aspect ratio and under different normal loads fails at higher strain than if there is no fiber. Figures $\mathbf{7}$ and $\mathbf{8}$ show the effect of type B fiber on shear strength of sand under two normal loads $28 \mathrm{kPa}$ and $110 \mathrm{kPa}$ at $4 \%$ fiber content by dry weight of the sand.

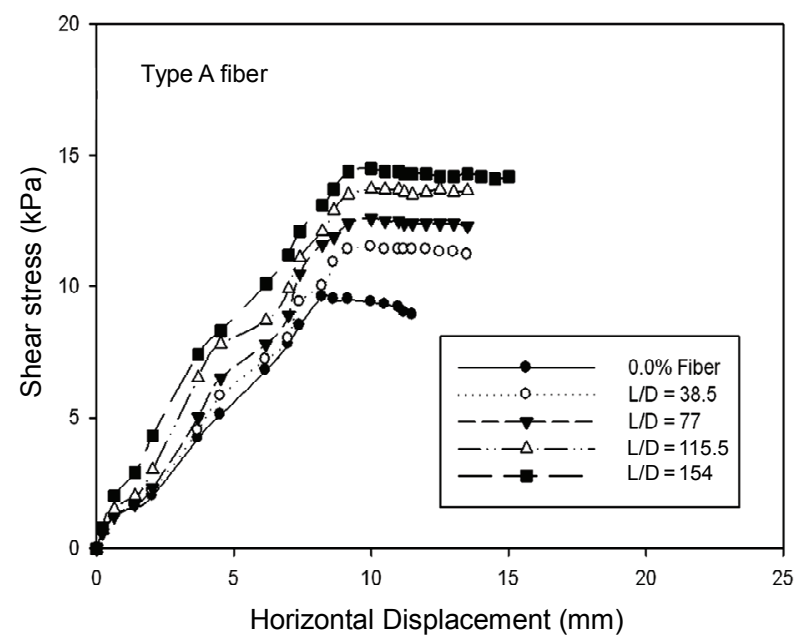

Figure 5. The effect of the aspect ratio on the shear strength of the sand at normal load $28 \mathrm{kPa}$ at $4 \%$.

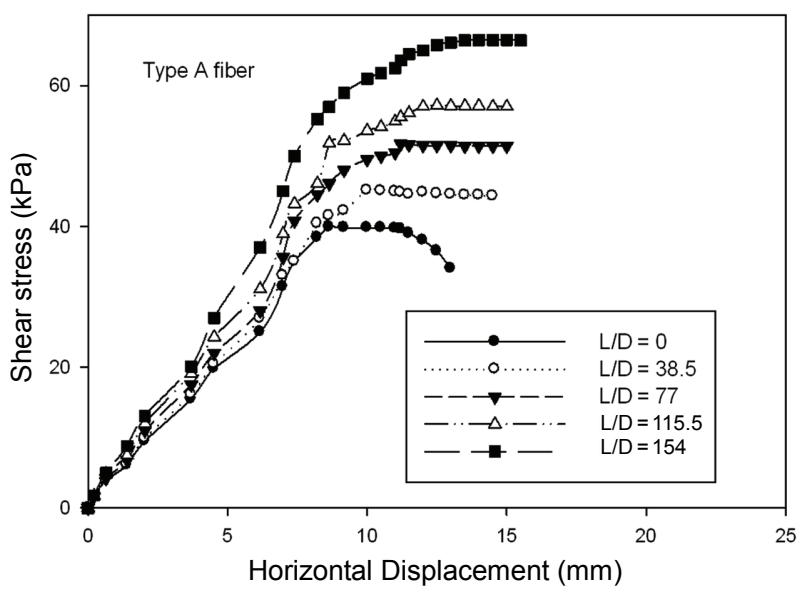

Figure 6. The effect of the aspect ratio on the shear strear strength of the sand at normal load $110 \mathrm{kPa}$ at $4 \%$ type $\mathrm{A}$ fiber.

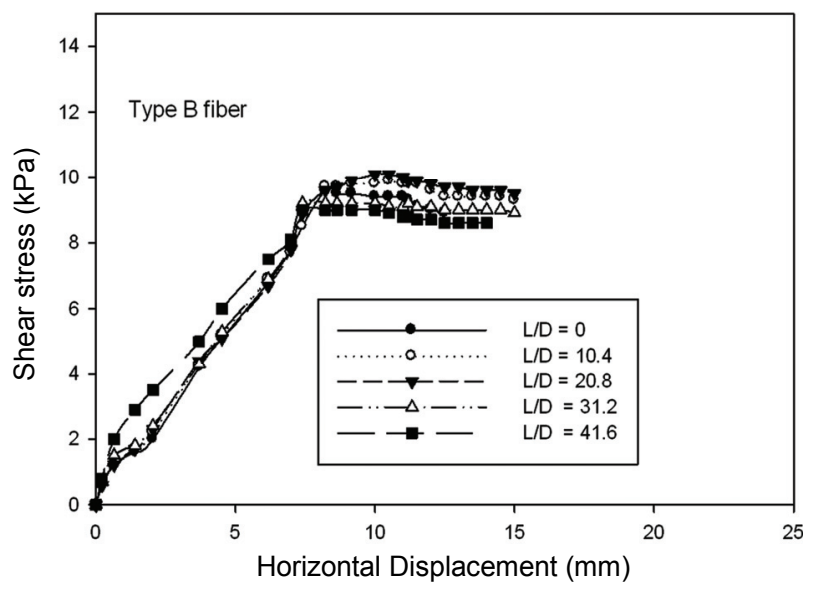

Figure 7. The effect of the aspect ratio on the shear strength of the sand at normal load $28 \mathrm{kPa}$ at $4 \%$ type $B$ fiber.

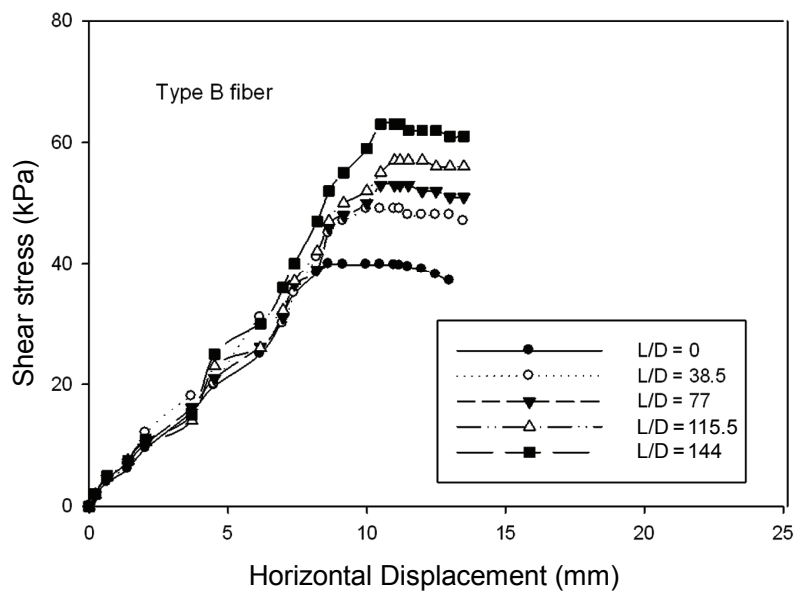

Figure 8. The effect of the aspect ration on the shear strength of the sand at normal load $110 \mathrm{kPa}$ at $4 \%$ type $B$ fiber. 
It is clear from Figure 7 that the type B has a small or no effect on shear strength if the aspect ratio is less than $20.8(\mathrm{~L}=1.0 \mathrm{~cm})$. Increasing the aspect ratio of more than 20.8 will result in decreasing the shear strength. The shear strength decreased from $9.6 \mathrm{kPa}$ to $9.2 \mathrm{kPa}$ and $8.6 \mathrm{kPa}$ when the aspect ratio increased from 10.4 to 31.2 and 41.6 respectively. The reduction in shear strength was noticed in all samples tested under at small normal load equal to $28 \mathrm{kPa}$. This behavior can be attributed to the plastic-like-surface which makes the sand particles moves and slip over that surface easier resulted in decreasing the shear strength.

The effect of aspect ratio of type B fiber on shear strength under high normal load is shown in Figure 8. This figure indicated the increase in the aspect ratio will increase the shear strength under normal load $110 \mathrm{kPa}$. The shear strength increased from $49 \mathrm{kPa}$ to $63 \mathrm{kPa}$ when the aspect ratio increased from 10.4 to 41.6. This can be explained as the following. As the normal load increased, the contact surface between sand and the crimpled surface of the fiber increased. This increase in the contact surface makes the sand particles harder to move and thus increasing the shear strength of the sand.

\subsection{The Effect of Aspect Ratio on Angle of Internal Friction}

The effect of aspect ratio both fibers on the angle of internal friction angle of internal of the sand was studied on Figures 9 and 10. Figure 9 shows that the increase in the aspect ratio results in increasing the angle of internal friction of the sand. This increase was noticed under all different loads. The angle of internal friction increased from $19^{\circ}$ to $31^{\circ}$ when the aspect ratio increased from 0.0 to 154 under normal load equal to $110 \mathrm{kPa}$. The increase in the angle of internal friction will result in increasing

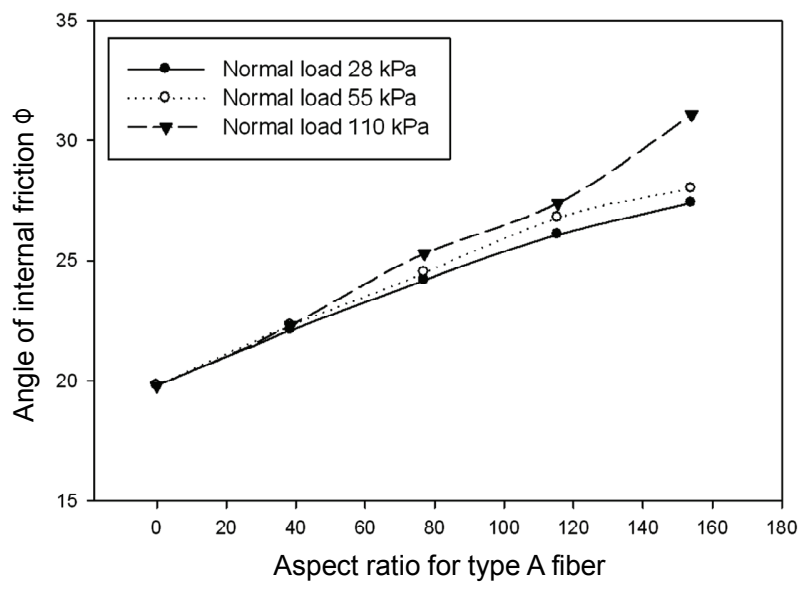

Figure 9. The effect of aspect ratio of type $A$ fiber on the angle of internal friction under three different normal loads.

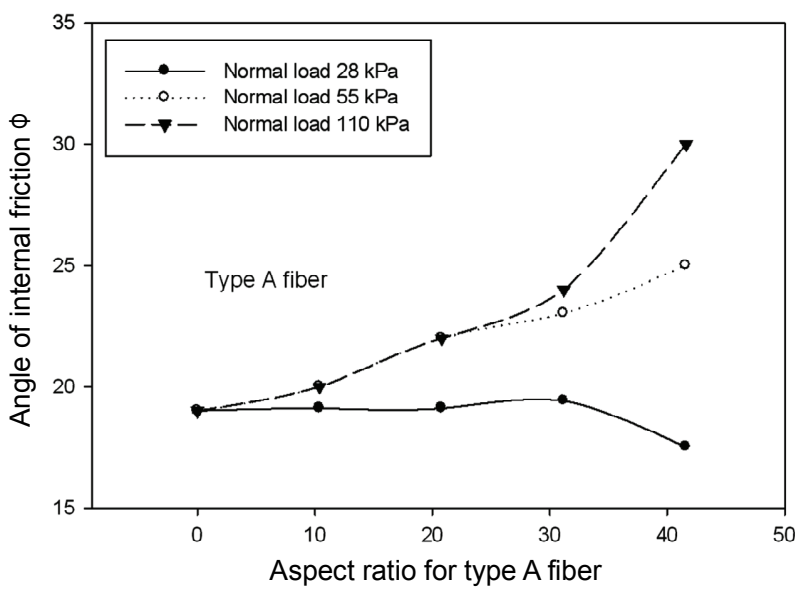

Figure 10. The effect of aspect ratio of type $B$ fiber on the angle of internal friction under three different normal loads.

the shear strength of the sand. Figure 10 studied the behavior of sand due to the addition of type B fiber under three normal loads. As it is shown in this figure the aspect ratio has no effect on the angle of internal friction of the sand under a normal load of $28 \mathrm{kPa}$. The angle of internal friction remains about $19^{\circ}$ at $10.4,20.8$ and 31.6 aspect ratios. As the aspect ratio increase more than 31.6 it was noticed that the shear strength decreased. On the other hand and as the normal load increased, it was noticed that the angle ofinternal friction increased. The increase become larger at higher normal load and the angle of internal friction increased from 10 to 30 at normal load equal to $119 \mathrm{kPa}$ and aspect ratio equal to 41.6 .

\section{Practical Consideration}

The results of the study have shown that addition of polypropylene fibers to sandy soil have improved significantly the physical engineering properties. These fibers may be used practically to increase the shear strength of sand especially under high loads. The result from this research concludes that the two types of polypropylene fibers could be promising materials and can be mixed with sandy soils in different construction projects to increase sand shear strength with the exception to use type $\mathrm{B}$ fiber at high normal stresses.

\section{Conclusions}

This research presents the results of using two polypropylene fibers at different percentages and different aspect ratio to improve the some physical properties of sandy soil. Based on the test results of this study, the following conclusions may be drawn out:

1) The shear strength of sand increased by increasing 
the percentage flat profile fiber with high flexibility (type A fiber). The increase of in the percentage of the crimped profile fiber with high relative stiffness (type B fiber) increased the shear strength at high normal stress.

2) The increase of the percentages of the both type of fiber will result in increasing the angle of internal friction of sand.

3) The ductility of sand increased by adding the two types of fibers.

4) The increase in the aspect ratio resulted in increasing the both the shear strength of the sand and angle of internal friction. Butter results can be obtained at high.

5) The sand showed no peak strength at the four percentages of fibers.

\section{References}

[1] M. F. Attom, "The Effect of Compactive Energy Level on Some Soil Properties," Applied Clay Science, Vol. 12, No. 1-2, 1997, pp. 61-72.

[2] I. Yilmaz and B. Civelekoglu, "Gypsum: An Additive for Stabilization of Swelling Clay Soils," Applied Clay Science, Vol. 44, No. 1-2, 2009, pp. 166-172.

[3] A. A. Al-Rawas, A. W. Hago and H. Al-Sarmi, "Effect of Lime, Cement, and Sarooj (Artificial Pozzolan) on the Swelling Potential of an Expansive Soil from Oman," Building and Environment Journal, Vol. 40, No. 5, 2005, pp. 681-687.

[4] K. M. A. Hossain, M. Lachemi and S. Easa, "Stabilized Soils for Construction Applications Incorporating Natural Resources of Papua New Guinea," Resouces Conservation and Recycling Journal, Vol. 51, No. 4, 2007, pp. 711-731.

[5] E. Kalakn, "Effects of Silica Fume on the Geotechnical Properties of Fine-Grained Soils Exposed to Freeze and Thaw," Cold Regions Science and Technology, Vol. 58, No. 3, 2009, pp. 130-135.

[6] J. D. Nelson and D. J. Miller, "Expansive Soils: Problems and Practice in Foundation and Pavement Engineering," John Wiley and Sons Inc., New York, 1992.

[7] M. M. Abu-Zreig, N. M. Al-Akhras and M. F. Attom, "Influence of Heat Treatment on the Behavior of Clayey Soils," Applied Clay Science, Vol. 20, No. 3, 2001, pp. 129-135.
[8] K. L. Lee, B. D. Adams and J. M. Vagneron, "Reinforced Earth Retaining Walls," Journal of Soil Mechanics and Foundation Division, ASCE, Vol. 99, No. 10, 1973, pp. 745-764.

[9] S. W. Park, R. L. Lytton and J. W. Button, "Forensic Investigation of Pavement Distortions Using Soil Suction," Journal of Transportation Engineering, Vol. 125, No. 1, 1999, pp. 60-66.

[10] M. N. Fatani, G. H. Bauer and N. Al-Joulani, "Reinforcing Soil with Aligned and Randomly Oriented Metallic Fibers," Geotechnical Testing Journal, Vol. 14, No. 1, 1991, pp. 78-87.

[11] S. Ziegler, D. Leshchinsky, H. I. Ling and E. B. Perry, "Effect of Short Polymeric Fibers on Crack Development in Clays," Japanese Geotechnical Society, Vol. 38, No. 1, 1998, pp. 247-253.

[12] T. Yetimoglu and O. Salbas, "A Study on Bearing Capacity of Randomely Distributed Fiber-Reinforced Sand Fills Overlying Soft Clay," Geotextiles and Geomembranes Journal, Vol. 23, No. 2, 2003, pp. 174-183.

[13] M. Esna-ashari and M. Asadi, "A Study on Shear Strength and Deformation of Sand Soil Reinforced with Tire Cord Waste," Proceeding the Fourth Asian Regional Conference on Geosynthetics, Shanghai, China, 2008, pp. 355359.

[14] D. H. Gray and H. Ohashi, "Mechanics of Fiber Reinforcement in Sand," Journal of Geotechnical Engineering, ASCE, Vol. 1109, No. 3, 1983, pp. 335-353.

[15] T. Park and S. A. Tan, "Enhanced Performance of Reinforced Soil Walls by the Inclusion of Short Fiber," Geotextile and Geomembrene Journal, Vol. 23, No. 4, 2005, pp. 348-361.

[16] D. R. Freitag, "Soil Randomly Reinforced with Fibers," Journal of Geotechnical Engineering, ASCE, Vol. 112, No. 8, 1986, pp. 823-826.

[17] S. Kumar and E. Tabor, "Strength Characteristics of Silty Clay Reinforced with Randomly Oriented Nylon Fiber," Electronic Journal of Geotechnical Engineering, Vol. 127, No. 9, 2003, pp. 774-782.

[18] Y. Cai, B. Shi, C. W. W. Ng and C. Tang, "Effect of Polypropylene Fiber and Lime Admixture on Engineering Properties of Clayey Soil," Engineering Geology Journal, Vol. 87, No. 3-4, 2006, pp. 230-240. 